\title{
Harmonizing IT Frameworks and Agile Methods: Challenges and Solutions for the case of COBIT and Scrum
}

\author{
Necmettin Ozkan \\ Information Technologies Research and \\ Development Center Kuveyt Turk \\ Participation Bank Kocaeli, Turkey \\ necmettin.ozkan@kuveytturk.com.tr
}

\author{
Ayca Kolukisa Tarhan \\ Computer Engineering \\ Department Hacettepe \\ University Ankara, Turkey \\ atarhan@cs.hacettepe.edu.tr
}

\author{
Burak Gören \\ Vice President of Agile Governance, \\ DevOps and Lead Agile Coach \\ Akbank Kocaeli, Turkey \\ burak.goren@akbank.com
}

\author{
İsmail Filiz \\ Problem, Service Level and Quality Assurance Manager \\ Akbank Kocaeli, Turkey ismail.filiz@akbank.com
}

\author{
Enis Özer \\ Agile Coach Akbank Kocaeli, Turkey \\ enis.ozer@akbank.com
}

\begin{abstract}
Information Technology (IT) is a complex domain. In order to properly manage IT related processes, several frameworks including ITIL (Information Technologies Infrastructure Library), COBIT (Control OBjectives for Information and related Technologies), IT Service CMMI (IT Service Capability Maturity Model) and many others have emerged in recent decades. Meanwhile, the prevalence of Agile methods has increased, posing the coexistence of Agile approach with different IT frameworks already adopted in organizations. More specifically, the pursuit of being agile in the area of digitalization pushes organizations to go for agile transformation while preserving full compliance to IT frameworks for the sake of their survival. The necessity for this coexistence, however, brings its own challenges and solutions for harmonizing the requirements of both parties. In this paper, we focus on harmonizing the requirements of COBIT and Scrum in a same organization, which is especially challenging when a full compliance to COBIT is expected. Therefore, this study aims to identifying the challenges of and possible solutions for the coexistence of Scrum and COBIT (version 4.1 in this case) in an organization, by considering two case studies: one from the literature and the case of Akbank delivered in this study. Thus, it extends the corresponding previous case study from two points: adds one more case study to enrich the results from the previous case study and provides more opportunity to make generalization by considering two independent cases.
\end{abstract}

Index Terms-agile, Scrum, information technology, COBIT, challenge, solution

\section{INTRODUCTION}

$\mathrm{T}$ HERE are many IT (Information Technology) process frameworks to guide organizations in their compelling environments. In order to properly manage IT related processes, several frameworks including ITIL (Information Technologies Infrastructure Library), COBIT (Control OBjectives for Information and related Technologies), IT Service CMMI (IT Service Capability Maturity Model) and many others have already emerged in recent decades. They commonly poses capabilities with a disciplined, sustainable, controlled, standard and consistent way of working for IT. Recently, there also exist Agile Software Development (ASD) methods and frameworks to add more agility to organizations in their complex software development processes. The use of such broad frameworks with their diverse and occasionally different characteristics in a same organization has a high possibility of emergence, posing some challenges on the side of practitioners.

As one of them, providing organizations mainly a level of control and assurance, COBIT has a domination in IT field for many years. With its more than 40 international integrated standards, it is a framework providing IT governance to help in delivering value from IT and managing risks associated with IT [4]. Many countries listed in [5] including USA, Canada, Australia, India, Japan, Brazil, Poland, Romania, South Africa, Turkey facilitate COBIT for their public sectors, governmental agencies and regulatory bodies. In particular, in Turkey, since May 2006, the banks have started to use COBIT, widely with control and audit ground. This control and audit based usage is the main driver to keep the COBIT v.4.1 as the valid version for the banks in Turkey and to cover in this particular study, rather than the further versions.

On the other side, adoption of the ASD is increasing, especially with its most widely used framework, Scrum [6]. Considered the coverage of Scrum and COBIT and Scrum's penetration especially in large organizations [2, 7], a coexistence of them in a same organization has a possibility of emergence [1]. However, the ASD approaches, defined with the ability to respond to change, have generally been regarded as contrary to the traditional (heavyweight, disciplined, predictive, plan-driven) approaches due to opposing viewpoints $[8,9]$. COBIT, as a representative of heavyweight, disciplined, predictive, plan-driven approaches, has no exception in this regard. It has a co-occurrences and similarities with the rationalized, engineering-based approaches. Thus, melting COBIT and Scrum in the same organization can be intriguing yet challenging (especially when a full compliance with COBIT is required as in the case of the banks in Turkey) [1,2], as shown with the results from this study.

Despite the challenges, the charm of being agile attracts organizations to go for the Agile transformations [2, 7] and manifests a need to study the possible challenges of and solutions for COBIT-Scrum coexistence to guide the organizations. COBIT defines itself as a framework and allows tailoring with specific needs of organizations. However, in some countries such as Turkey, COBIT is applied 
in a strict way such as a regulation rather than a guide, with less chance to tailor. One way or another, there is at least a need to address to which parts of COBIT are required to pay attention in a Scrum implementation.

In this study, we search for a proper coexistence of the ASD - as demonstrated by Scrum - with the realities of IT needs in an organization - as predefined by COBIT. Accordingly, this paper focuses on the identification of challenges and proposing solutions for the identified challenges for a possible Scrum implementation within a COBIT-driven environment, by considering two case studies: one from the literature and the case of Akbank delivered in this study. It extends the works of [1-3] from two points: adding one more case study, to enrich the results from previous case study and providing more opportunity to make a generalization by considering two independent cases. More specifically, this study has two research objectives, as the following:

- RO1: To elicit and identify challenges that arise in harmonizing the requirements of COBIT and Scrum,

- RO2: To propose and discuss solutions for the identified challenges.

The remaining of this work is organized as follows. We provide the related works in Section II. The research methodology is delivered in Section III. In Section IV, the challenges identified as relevant to RO1 are communicated. In Section V, the case study is delivered. In Section VI, solution suggestions relevant to RO2 are provided. In Section VII, the subject is evaluated with discussions. Finally, in Section VIII, conclusions and future work are delivered.

\section{RELATED WORKS}

In order to reach a set of related works, a search with the keyword of "Scrum COBIT" was conducted throughout of libraries of ACM Digital Library, IEEE Xplore, Web of Science, Science Direct and Scopus, with their default search settings and without any specific filter in the year range. Relatively a small number, 42 peer-reviewed works (from workshops, conferences, journals and book chapters) in total were returned in English and examined through their titles and, where necessary, abstracts and/or full texts. It is seen that some works covers COBIT and Scrum different from yet within related context to our study. Among them, Aguillar et. al [10] comes with a case study where the COBIT 5.0 Process Assessment Model was used to identify processes that need improvements within the studied company. It was then applied to Scrum to integrate internal activities and processes. Study [36] aims to eliminate some known challenges of COBIT 5 adoptions by providing a Scrum based methodology and demonstrates better results in terms of commitment from top management and alignment. Study [38] proposes a model type artifact for software development governance, mainly based on COBIT 5 and Scrum. Study [39] use COBIT through identification, description and evaluation of general roles and structures related to the notion of project, to unite the project related entities with Scrum that are not explicitly included in Scrum. In the study [40], the authors use the indicators of COBIT for measuring Scrum-based software development.

Directly related to our study, studies of $[1,37]$ aim to identify potential challenges in a possible Scrum and COBIT coexistence in an organization, without providing any solutions to the challenges. Studies of $[2,3]$ provide the experiences based on a single case of a bank in Turkey that operates with Scrum and COBIT co-occurrence, and therefore has some natural limitations and a specific window to the case. It should be noted that the challenges identified in [1, 2, 3, 37] are considered, refined, improved and justified in this study. The solutions proposed by [2] and [3] are considered, refined and improved, especially by another case study, in order to eliminate the context-based distortions of that particular case and aims to make the subject more generalizable.

\section{RESEARCH METHODOLOGY}

It is a fact that Scrum more or less touches all the COBIT processes that are 34 in number, with 210 control objectives and 990 control practices. As COBIT presents a huge area to work with, it is a must to focus on the processes that Scrum affects directly. In identifying the related COBIT processes with a direct and intense relevance with Scrum, the study of Ozkan [1] was taken into consideration as it provides the comprehensive COBIT process list in this regard and the reasons to select them.

Among the processes, regarding PO1 (Define a Strategic IT Plan), the study of Ozkan [1] covers two topics addressed in PO1.1 (IT Value Management) and PO1.2 (Business-IT Alignment) respectively. The mentioned issue within the scope of "IT Value Management" is the early warnings of any deviations from the plan, including cost, schedule or functionality, which can be possibly met by the frequent feedback and high transparency mechanisms in Scrum. As the second issue, establishing fair, transparent, repeatable and comparable evaluation of business cases and providing the business and IT alignment and integration as pointed out in COBIT are among the common issues regardless of the development method applied. It thus leads to exclude PO1 process from the list. The fact that both case studies covered in this study do not provide any clues about these matters reinforces this exclusion. The list of the remaining processes includes PO4 (Define the IT Processes, Organization and Relationships), PO7 (Manage IT Human Resources), PO10 (Manage Projects), AI1 (Identify Automated Solutions), AI2 (Acquire and Maintain Application Software), AI4 (Enable Operation and Use) AI7 (Install and Accredit Solutions and Changes).

After the identification of these seven COBIT processes, a comprehensive and thorough investigation of the challenges was done by the first author. In doing so, a profound reading of the Agile values and principles [20] and the Scrum Guide [11] on one side and COBIT 4.1 [4] on the other side was conducted. If further detail is needed for a particular COBIT process, COBIT Control Practices [19] sustaining each related control objectives with detailed control practices were used. For the notations used in this study, control objectives are remarked as in "AI2.1" and control practices as in "AI2.1.3" with parentheses in the appropriate places in the content. In identifying the challenges of the processes, additionally, the studies of [1], [2], [3] and [37] were considered. Besides, the case study of Akbank in Turkey was used to justify and, if needed, to update the list of challenges, by asking to the interviewees if the current identified challenges are valid and if there is any additional one. With this justification in the case study, one item - Alignment of the Audit Perspective with Agile Approaches - was added and the rest of the list was maintained. The final set of the challenges are delivered and explained in the next section. 
After the identification of the challenges, the possible solutions were proposed based on, but not limited to, two case studies; one delivered in the studies of Ozkan, Tarhan and Kucuk [2] and Ozkan [3] and the second one from the case of Akbank delivered in our study. The first case was selected as it delivers the most comprehensive results, as far as we know, in the context of our study. Additionally, the first author's experiences, apart from these two case studies, were involved in proposing the final solutions. In the identification of challenges and corresponding solutions, however, this paper aims to eliminate the context-based distortions of these particular cases and to make the subject more generalizable.

For the case of Akbank delivered in our study, semistructured interviews were conducted with three people from the bank by the first author of this paper. Being also the coauthors of this paper, one of the three involved people is the Vice President of Agile Governance, DevOps and Lead Agile Coach, the second one is an Agile Coach and the last one is the Quality Assurance Manager involving with COBIT intensively. Two meetings, which lasted three hours in total, were held, and during the meetings, the identified challenges were conveyed by the first author, and they were asked whether these challenges are valid for their case and whether there are any other challenges. The first author did not mention any solution suggestions in order to avoid bias, and they were asked to convey their own solutions to these challenges. The interview contents were noted down by the first author and then sent to the interviewees for the confirmation and then necessary updates were made.

\section{CHALLENGES}

This part of the paper communicates the descriptions of challenges identified. The source of the challenges falls into two categories: 1) those coming from the alterations resulted from a Scrum adoption and COBIT has an emphasis on the same points that Scrum alters. This type does not necessarily create a conflict between the two sides yet organizations should pay extra attentions to meeting COBIT requirements especially during the Scrum transformation. This type of challenges is called as "concern" in this work. 2) The second type of challenges are those that COBIT and Scrum have different perspectives on. This type is a matter of a clear "conflict" that organizations should deal with. The category which is classified as "concern" is likely to be more in terms of number. Here, it was aimed to give a place to those that are fundamental and primary.

\section{A. Steering Committee (Conflict)}

PO4 (Define the IT Processes, Organization and Relationships) points out one or more steering committees to determine prioritization of IT-enabled investment programs. Schwaber and Sutherland [11] state for the same issue: "The Product Owner is one person, not a committee. The Product Owner may represent the desires of a committee in the Product Backlog, but those wanting to change a Product Backlog item's priority must address the Product Owner." According to the Scrum Guide, Product Owner is the ultimate decision point in prioritization of the projects, and it is the steering committee according to COBIT.

\section{B. Segregation of Duties (Conflict)}

Scrum recognizes no specific titles inside the development team other than developer, giving the accountability to the development team as a whole [11]. From the window of COBIT, this restricts the controls to preclude full segregation of duties as mentioned in PO4.11 such as in conducting functional tests [1]. Similarly, AI7.6.1 clearly states that "ensure that the testing is designed and conducted by a test group independent from the development team". Additionally, in (AI2.8) Software Quality Assurance, COBIT states that"...ensuring that reviewers are independent from the development team".

\section{Human Resource Management (Concern)}

Accountabilities and responsibilities of functions of teams related to personnel recruitment, retention (PO.7.1), termination (PO.7.8), competencies management (PO7.2), adhering to codes of ethics (PO7.3), dependence upon individuals (PO7.5), reliance on a single individual performing a critical job function (PO4.13) in the context of tacit knowledge, performance evaluation (PO7.7) and administrative operations largely directed and managed by line managers in the traditional methods should be addressed in Scrum [1]. However, Scrum does not specify techniques to address the human side of software development [41]. Regarding the performance evaluation, showing confidence in producing team's own data to reflect their own performance possibly in a way for the sake of personal favors may become a dilemma. Career path development (PO7.2.4) is a matter of Scrum that provides a flat structure of organization for teams, especially for those regarding people management experience valuable [1].

According to [1], regarding PO4.4.3, the workload and resource capacity management among and inside the Scrum teams has not been detailed out in terms of who is responsible for deciding on the staff capacity of the teams, in order to response adequately to business needs. PO.4.5.2 extends this issue by adding "the use of external contractors and flexible third-party" that may not have the Scrum capabilities. AI2.7.5 highlights the same issue by stating that "when third-party developers are involved with the applications development, establish that they adhere to contractual obligations and organizational development standards..."

\section{Project Management (Conflict)}

COBIT poses a traditional project management approach with requirements for assessing of schedule, budget and scope of projects (PO10.6.3), reviewing and approving cost, schedule, scope and quality changes in the project baseline (PO10.11) by key stakeholders and project sponsors (PO10.5.2), integrated project plan (PO10.7) with work breakdown structures and identification of critical paths, forming and acquiring a project team with its competent staff members (PO10.8) and a project governance structure including project office and project manager roles (PO10.3). However, in Scrum, the notion of project, project management and project manager role are deliberately left blank [12].

\section{E. SDLC (Conflict, Concern)}

As a "Conflict", in the SDLC processes in COBIT, it is expected to create certain document contents with a certain order (for instance, preparing detailed design before coding is initiated) and to approve them by relevant parties. Thus, COBIT has a potential to make Scrum's each sprint to resemble mini-waterfall in flow [2] by posing requirements of some check-points and a sequential flow in a usual iteration. Within the coexistence COBIT and Scrum, iterative and incremental development results in iterative and incremental development of the relevant documents/contents for multiple times including requirements and feasibility decision and 
approval (AI1.4), high level design (AI2.1), detailed design (AI2.2), design of application security and availability (AI2.4) and application control and auditability (AI2.3), test plans (AI7.2), (AI7.3) and implementation plan (AI7.3) along with their formal approvals by related business process owners and IT stakeholders (AI1.4.1), (AI2.1.5), (AI2.2.11), (AI2.9.3), (AI7.2.8), (AI7.3.2).

As a "Concern", when combining such COBIT requirements with the frequency of (relatively short) Scrum sprints, naturally, the continuous integration probably including performance, stress, usability, security, system, integration, user acceptance, operational readiness, backup and recovery tests (AI7.2.5) "within a secure test environment representative of the planned operations environment relative to security, internal controls, operational practices, data quality and privacy requirements, and workloads" (AI7.4) may be overloading and time consuming even with a right balance between automated scripted tests and interactive user testing (AI7.6.3).

Similarly, iterative and incremental growth of the system calls for the creation and integration of complete, accurate and usable supporting documents (AI4.2) with promptly updates to the existing environment in production for the use of end users (AI4.3), operations and support staff (AI4.4), and business management (AI4.2) along with the required trainings (AI7.1.2) [2].

\section{F. Documentation (Concern)}

Documentation takes a fundamental role for COBIT as a means of storing, sharing, conveying, replicating and backingup knowledge, planning, codifying and standardizing of practice, and creating logs for further use [1]. On the other hand, although not stated theoretically, in practice, Agile approaches discourage documentation and they may consider documentation as a secondary activity [13].

\section{G. Alignment of the Audit Perspective with Agile Approaches (Concern)}

Depending on all these points above, the relevant methods of audit and control teams must change accordingly. This brings along the need for an alignment in the relevant audit and control perspectives and processes to the Agile approaches and vise verse.

\section{CASE STUDY: AKBANK IT}

Akbank is a leading bank in Turkey, which has long been applying Scrum in its IT. Akbank IT runs with 1400 people who are practicing Scrum with 161 Scrum Teams, 12 Product Group domains, 161 Scrum Masters, 109 Product Owners and four internal Agile Coaches. Agile Studio which is an in-house Agile coaching team and Agile Leaders team which is a transformation sponsor team at the highest-level lead for the Agile transformation and foster agility within the organization.

To justify the current challenges, identify additional ones and to propose solutions to the final set of the challenges, the first author of this paper conducted an interview with three experts from Akbank where all people participated. After reaching the final set of the challenges that were delivered in the previous section, the experts conveyed their own solutions to these challenges. The following sub-sections provide solutions applied by Akbank to the determined challenges.

\section{A. Steering Committee}

There is a two-stage flow to prioritize the projects. Running in the quarterly period, at the first stage, the senior executives of each business unit promote the projects they want to develop, to all other business unit participants. Product owners are not a member of this committee, since the product owners have a perspective on the product line and do not provide a comprehensive perspective that cuts multiple products and services horizontally. At this level, an enterprise level alignment and orientation towards the same goal are assured through some methods such as linking projects to the annually defined strategy areas and determining value and expected contributions of the project proposals in tangible terms. Towards the end of this stage, a prioritized project list is achieved, by means of the votes of all business unit stakeholders.

Following the ordering of the projects, at the second stage, the prioritized project list is conveyed to IT. With the participation of the product owners, portfolio managers, product group leaders, a meeting is conducted for the alignment and collaboration between the POs and discussing priorities, risks and inter-team dependencies of teams. In this meeting, the project list is evaluated in terms of capacity, high level planning and product management perspective. A master product owner is determined for each project and the dependencies between the relevant products are identified and evaluated. Finally, an agreement is reached between the relevant product owners, and if necessary, the orders of the projects is revised accordingly. At the end of the quarterly period, the ranking at the first stage is re-operated with a new list of that moment to response to the needs of the current time. The loop thus repeats, with the new list.

\section{B. Segregation of Duties}

The accountability with a customer-request-based testing is appointed to one specific person in the team to ensure that tests are carried out appropriately. This person can wear any role from the development team (developer, analyst, tester, etc.). Naturally, the person performing the functional tests should be different from the person who codes. For the software quality assurance, there is a separate team outside the development teams to control the flow and creation of documentations throughout the end-to-end process. Even if the quality assurance team is located online with the development teams, their approval is just before the transition to the production environment. The main reason for the positioning of this stage is that the content changes dynamically during the development, reaching its final state when getting closer to the transition.

\section{Human Resource Management}

There is no team manager in the new structure, yet there still exist department managers, newly positioned as product group leaders. Although the Human Resource Department exhibits no radical changes in its current practices after the transformation, the development teams have more voice in the human resource related processes. For instance, the teams can design their candidate profiles and run the recruitment process themselves along with the Human Resource Department.

The career path to the conventional line management have been replaced with the new path built on the expertise of the team members. In this way, the career path has been widened instead of narrowing down at a management level. There are two main legs feeding the performance management: team- 
based and individual-based evaluation. The majority of the score comes from the team-based score, and most of this team score is fed from metrics such as problem cases, interruption records. Additionally, the customers and associated teams evaluate the whole team as one unit. For the individual evaluation inside the teams, as the second leg, the department managers assess the individuals and additionally the members of the team assess the other members within his/her team. The team-based evaluation taking more weight on the final score is combined with individual-based evaluation to create the ultimate output. Throughout the all process, the targets are assigned team-based, customer-focused and on the final value.

In capacity management, considering teams' capacity as master, the teams are fixed around the products in terms of structure and do not organize dynamically around business projects. In case of a capacity shortage of the teams meaning that they will not satisfy business priorities for a particular period, some options emerge; if this shortage indicates a permanent situation, the static team structures are arranged accordingly. If the particular supply-demand imbalance is for a temporary case and an action is required for it, a separate temporary team is formed with the people gathered from the teams, and disbanded when the development of the project is finished. If the imbalance seems for a long-term situation, the product teams are re-arranged accordingly.

\section{Project Management}

The project notion is maintained, but there is no project manager role. If the project is within the scope of a single development team, the relevant product owner follows the project. In case of the distribution of the project to more than one team, the PO of the main team follows the project. In new projects, the first connection between the customer and the development team is established with the mediation of the portfolio managers. Afterwards, it is ensured that the product owner and the customer establish a one-to-one relationship between them. The portfolio managers then take a position that supports customers mostly about the progress of their projects in the portfolio.

\section{E. $S D L C$}

The SDLC processes flow over the product-based teams. For this reason, the Sprint 0 step, which is suitable in the project-based formations, is not located. The approvals of the design documents given by the business and IT have been taken to the end of the releases (instead of sprints). There is no sprint-based approvals of the development documents because during the sprints, the customers view the product itself, not via a proxy of it with some documents. Until the tool support receives, the business unit approvals are being given by the product owners. For the IT side, the approvals given by a member from the development team is sufficient. Additionally, the approvals given by the central bodies such as security, enterprise architect and infrastructure teams remain. A DevOps team is located to manage certain central operations such as code base management, promotion to production and as well as to penetrate the DevOps culture into the organization.

\section{F. Documentation}

There are mainly two tools in supporting documentation: Jira and Microsoft TFS. Jira manages the pipeline where the product is offered to the customer. TFS is like the kitchen of the developers. With the support of these tools, the document contents expected to be produced are followed up.

\section{G. Alignment of the Audit Perspective with Agile Approaches}

In finding the middle way between internal control systems and Agile approaches, it is helpful to expose that sometimes COBIT and Agile methods propose different ways to eliminate the same concern. In this regard, Agile methods in certain areas provide more advantages compared to the COBIT proposals. For example, for the software development processes, the associated COBIT controls with the purpose of not deviating from the customer requirements are met with the short iterations in Scrum. In such cases, the corresponding control objectives lose their meaning in the context of agile working. However, some controls (for example, obtaining approval from customers for the development documents) should stay valid and be maintained. For the alignment in this context, many trainings were provided to the internal control and audit teams to show and persuade for how the main concerns of the corresponding control or audit processes are met by the agile way of working.

\section{SOLUTIONS}

This section suggests the solution proposals for the identified challenges in a unified view based the two case studies: the case of Akbank and the other one conveyed in the studies of $[2,3]$. It is noted that while the solutions proposed are based on the case studies, they are not limited to them; the first author's experiences gained during the case study delivered in $[2,3]$ were also integrated in building the solution proposals.

\section{A. Steering Committee}

COBIT mentions who constitutes the steering committee in general by stating the members from IT and business and then the product owners can be a member of the committee. Another point is that the fair position of POs and operations of processes under their reasonability play very critical role [1]. Similarly, PO4.4.2 (Organizational Placement of the IT Function) emphasizes to "define and fund the IT function in such a way that individual user group departments cannot exert undue influence over the IT function and undermine the priorities agreed upon by the IT steering committee". With a structure of the balanced power of relevant parties reduces the risk POs bear who are solely one person according to the Scrum Guide [11]. Or, in a more-Scrum-way, "the product owner may represent the desires of a committee in the product backlog, but those wanting to change a product backlog item's priority must address the product owner".

\section{B. Segregation of Duties}

For the sake of the nature of the work, a developer should not be allowed to make functional tests for his/her code, as $\mathrm{s} /$ he can naturally be blind to what $\mathrm{s} /$ he codes. However, it does not mean to follow literally the COBIT's suggestions in this regard. COBIT regards the test groups and development teams as separate bodies, which is not the case in Scrum teams. Similarly, the teams as a whole can be responsible for their software quality assurance activities as the process assurance covers the team wholly. Alternatively, the team may delegate this responsibility to another body outside of the team if a central body dedicated to the software quality assurance reviews is located, as in the case of Akbank.

\section{Human Resource Management}

Regarding the operations of human resource management including personnel recruitment, retention, termination, 
competencies management, adhering to codes of ethics, it is possible to delegate those activities to the certain parts of the organization, as seen in the both cases. The development teams will probably get more responsibilities than of those in the traditional approach. Such a distribution also helps to avoid possible narrow throats. Additionally, decision makers can be supported with inputs from evaluations of the teams inside and from parties around the teams. For the career path development, it can be possible to add positions not in hierarchy based on the new way of working which can be promoted by evaluating the experience, knowledge, skills and contributions, as proposed by [2].

Scrum is powerful in knowledge sharing and the rotation of team members enables the knowledge not monopolized by a few roles [14]. As mentioned in the "Documentation" section of this study, utilizing documentation, process and tool capabilities will also help in minimizing dependence upon key individuals such as PO who performs critical operations including maximizing the value (PO4.13 in relevant), managing relationships between IT and key stakeholders (PO4.15.2 in relevant). Considering PO is a sole person, as pointed out in (PO4.13.4), Scrum should additionally assure this critical person's appropriate availability during time-off periods, vacations and leaves of absence (PO7.5) [1].

To facilitate IT functions to support the business with appropriate and flexible resource arrangements, even when involving external contractors and third parties, the concept of project and project management can be injected into Scrum in an agile way. The details of proposed solution are elaborated in "Project Management" section of this paper.

The personal-level performance measurement should not be preferred in Scrum because it inhibits the team spirit. In this manner, when the team-level performance measurement is preferred, the following points should be considered [2]:

- Teams are not fully isolated from their environments and there are inter-team boundaries at many cases. Thus, a special attention should be paid to identify and, if possible, to separate the borders between the teams in the performance measurement.

- Be aware of the dilemma of using the metrics both for performance measurement context and improving teams themselves meanwhile.

- It may not be always visible to identify low and high level performance of individuals in a team from a point outside of the team, then let the team identify them transparently.

- Intend to strike a balance between maintaining the team spirit and providing individual measurement visibility.

- When appropriate, use assessment of people instead of measurement of them.

\section{Project Management}

IT currently is dominated by a process-oriented approach proposed by COBIT, service-oriented approach proposed by ITIL (Information Technologies Infrastructure Library), and a project-oriented approach proposed by PMBOK [15]. Although the product-oriented development is de-facto in the industrial production, the case is different in the IT field. The thinking has shifted from the pure product focus to a combination of service and product [16], and the pure product concept is prone to disappear behind service, especially in the banking sector. Unlike the context of the industry, in the software field, the development process is complex and dynamic and it deserves an interest at least as much as the result itself. As a result, regardless of the frameworks, to manage this complex and dynamic development processes, the concept of project inevitably is a living phenomenon in IT [35]. The response of the Agile world to this fact reinforces it: tens of thousands of results including one by Schwaber [17], returning from Google Scholar search with "agile project management" keyword, even for the time being. In parallel, in the both case studies, the project phenomenon was seen to exist.

This study comes with the idea of having a proper project definition aligned with PMBOK [18] which states: "project is a temporary endeavor undertaken to create a unique product, service or result". The term temporary means it has a defined beginning and end in time, and therefore defined scope and resources. This definition can fit with "Scrum-type-projectmanagement", in which the defined beginning and end in time, scope and resources can be dynamic with rules, policies etc., rather than with static numbers, at the run time based on (dynamic) value of the (other) projects.

Apart from the presence of the project phenomenon, organizations may prefer the project or product oriented team structures. While in the case study of $[2,3]$, both of these approaches are preferred, resulting in the product and project team existence together, while Akbank, although the phenomenon of project continues to exist, has settled only the product teams. Each of these options has its own advantages and disadvantages.

In fact, the Scrum approaches do not prefer a team structure shaped around the project concept, since project offers temporary teams that may damage the team spirit and thus not providing opportunity to establish a lasting basis for trust and performance of the teams. On the other hand, the management of the large-scale initiatives over the product teams may require distributing a whole (a customer epic) to the multiples development teams, if the specific initiative touches more than one product. This brings more dependency on the static entities (products) and weakens the flexibility that reinforces the agility. Such a disadvantage may imply the necessity for an abstract layer supported by the project notion with its encapsulation and unifying capabilities. Project enables gathering individuals around the project-specific teams rather than distributing a whole (a project) over the multiple teams, thus removing boundaries between the static product teams during the project. A project may also work for encapsulating the end-to-end solution developments, covering pre- and post-development stages including the project transition, trainings and creating user instructions and documentation materials [12]. Optionally, keeping the team members together during a project can be a way to unify people around a dedicated project team from probably different domains that are otherwise prone to become estranged to outer world and diverged from the central designs, structures and formations in time with their "selfsufficient" structures [15].

Project manager role can be in Scrum and it must be located when the circumstances call for it [12]. A separate project manager role might be beneficial even necessary in practice when it comes to larger projects [12]. Apart from the 
size, in hybrid environments, a project manager who works aligned with agile culture may [12]:

- Functions as a bridge for Scrum world to open it to places where Scrum does not exist, such as the rest of organization's classical structures.

- Plays a unifying role, free from methodology when Scrum is not preferably applied in all IT.

- When third party partners want to keep their own methodologies, plays as a unifying role for these two parts.

\section{E. SDLC (Software Development Life Cycle)}

The two frameworks mainly pose different approaches to the documentation requirements of SDLC, their approvals and level of discipline promoted by means of the processes. In order to reduce this tension between them, some points that can be useful may be as following [2]:

- It is possible to approach differently to the risk regarding the potential value at the future and the one posed to the production environments during the deployments. In this regard, depending on the risk appetite of the organization, the approvals of the design documents given by the business and IT can be taken to the end of the sprints or releases because the lost on the potential value can be at maximum as much as of a sprint/release length.

- It is helpful to organize the document requirements and their frequency based on projects, releases and sprints. However, the design documents should be iteratively and incrementally created and maintained per projects.

- If the project-based teams established, Sprint 0 as a step to identify and remove possible uncertainties around the project scope, cost, schedule and technical strategy can be beneficial for large and complex projects. There, adequate grooming can be made that is required for launching subsequent sprints. Apart from getting the big picture in design, this step can fortunately reduce the documentation overhead in the subsequent sprints.

- Organizations may locate additional roles for the approvals in the IT side including enterprise and domain architects to increase centralization.

Regarding the supporting documentations, adequate trainings and continuous integration/deployment of the system being promoted to production, it is clear that the COBIT requirements are independent from any kind of methodology, as the nature of the work calls for it. However, different from the design documents, those can be organized with a release frequency. For the continuous integration, test automation helps for the regression tests of corresponding increments. For frequent promotions to the production, providing secure and sanitized test environments as a representative of the future operating landscape that Scrum anticipates, is important [2]. For this reason, the frequency of updating the test environments with more frequently updated data is crucial. Moreover, DevOps initiatives can help to fasten and smooth the transition to the production.

\section{F. Documentation}

The documentation needs are valid for the developers [21] and the software to develop. If the software development requires documentation, this need of the development should be met. Thus, the Agile methods must decide where to place the balance in documentation [22]. In searching this place of balance, as members of the teams prefer simple and practical documentation techniques [23], lean (not necessarily agile) approaches aiming at avoiding unnecessary documentation should be preferred to reach 'just enough' documentation, that can be 'comprehensive', if required.

However, when considered the contrary natures of COBIT and Scrum in terms of the documentation approach, it requires a considerable effort to find a middle point between the documentary behaviors of Scrum's lightweight and dynamic characteristic and the COBIT's deterministic and massive documentation approach [2]. However, mitigating burdens on people coming with the COBIT documentation requirements arising with Scrum coexistence is necessary. It will result in more frequent documentation transactions to keep the documents updated. The use of the digital tools can help to manage such frequent document transactions and to lessen the burden on people to manifest their real productivity.

Similarly, the concept of tools and processes should be reconsidered for a right balance of digitization to create the capabilities for all the variance of time (past, present and future time), size (small-to-large) and location (distributed, collocated etc.) axis. Scrum should keep pace with the requirements of the digital age and benefit from the advanced digitization capabilities of this era (such as e-collaboration, electronic boards [24] and online-meetings) for people, by utilizing the documentation, process and tool capabilities.

\section{G. Alignment of the Audit Perspective with Agile Approaches}

To align the audit perspective with Agile approaches, the agile mindset need to be understood and adopted by the internal control and audit teams. For this, such teams may need a mindset, process and technology transformation. Thus, it would be beneficial to include these stakeholders as part of the trainings, at least.

The control side of the organizations such as the compliance and audit teams should open a proper space, give a time for Scrum and be open for a negotiation during the transformation. Seeking solutions for the new case should also manifest a new interpretations of and changes to the COBIT regulations. It may even be a need or chance to reconsider performance-conformance equation of the organizations and to adjust it accordingly.

Table-I summaries the challenges, the category of the challenges, the solution proposals and the points against to COBIT and/or Scrum and additionally indicates the source of the solution proposals. "Case 1" refers to the case delivered in the studies of [2,3], "Case 2" refers to the case of Akbank and "Author" refers to those proposed by the first author of this paper. If the proposal of the author is aligned with the application of the case(s), then "Author" statement was not added to the relevant item. 
TABLE I. LIST OF CHALLENGES AND SOLUTIONS

\begin{tabular}{|c|c|c|c|c|c|c|}
\hline $\begin{array}{c}\text { Challenge } \\
\text { Title }\end{array}$ & Challenge & $\begin{array}{l}\text { Category } \\
\text { of } \\
\text { Challenge }\end{array}$ & Solution of this Study & $\begin{array}{l}\text { Source of } \\
\text { the } \\
\text { Solution }\end{array}$ & $\begin{array}{l}\text { Points Against to } \\
\text { COBIT }\end{array}$ & $\begin{array}{c}\text { Points Against to } \\
\text { Scrum }\end{array}$ \\
\hline \multirow[t]{3}{*}{$\begin{array}{l}\text { Steering } \\
\text { Committee }\end{array}$} & \multirow[t]{2}{*}{$\begin{array}{l}\text { Conflict of interest } \\
\text { between PO and } \\
\text { steering committee }\end{array}$} & Conflict & $\begin{array}{l}\text { Product owners can be a } \\
\text { member of the committees }\end{array}$ & Author & - & $\begin{array}{l}\text { "those wanting to } \\
\text { change a product } \\
\text { backlog item's priority } \\
\text { must address the } \\
\text { product owner" / - }\end{array}$ \\
\hline & & Conflict & $\begin{array}{l}\text { Product owner may represent } \\
\text { the desires of the committee }\end{array}$ & $\begin{array}{l}\text { Partially } \\
\text { Case } 2\end{array}$ & $\begin{array}{l}\text { The ultimate } \\
\text { decision point in } \\
\text { prioritization of } \\
\text { the projects is the } \\
\text { steering } \\
\text { committee } \\
\text { according to } \\
\text { COBIT }\end{array}$ & - \\
\hline & $\begin{array}{l}\text { PO, one person, to } \\
\text { decide prioritization of } \\
\text { IT-enabled investment } \\
\text { programs with possible } \\
\text { influences of others }\end{array}$ & Conflict & $\begin{array}{l}\text { Product owners can be a } \\
\text { member of the committees }\end{array}$ & Author & - & $\begin{array}{c}\text { Scrum does not } \\
\text { necessarily mandate } \\
\text { product owners as a } \\
\text { member of any } \\
\text { committees }\end{array}$ \\
\hline \multirow[t]{2}{*}{$\begin{array}{l}\text { Segregation of } \\
\text { Duties }\end{array}$} & $\begin{array}{l}\text { Scrum's approach lets } \\
\text { a person to make } \\
\text { functional tests for the } \\
\text { functions he/she codes }\end{array}$ & Conflict & $\begin{array}{l}\text { A coder should not be } \\
\text { allowed to make functional } \\
\text { test for his/her code }\end{array}$ & Case 1,2 & - & - \\
\hline & $\begin{array}{l}\text { Testing and quality } \\
\text { review conducted by } \\
\text { an independent bodies }\end{array}$ & Conflict & $\begin{array}{l}\text { The team as a whole can be } \\
\text { responsible for software } \\
\text { testing and quality assurance }\end{array}$ & $\begin{array}{l}\text { (for } \\
\text { testing) } \\
\text { Case 1,2, } \\
\text { (for } \\
\text { quality } \\
\text { assurance) } \\
\text { Author } \\
\end{array}$ & $\begin{array}{c}\text { Not an } \\
\text { independent body }\end{array}$ & - \\
\hline \multirow[t]{6}{*}{$\begin{array}{c}\text { Human } \\
\text { Resource } \\
\text { Management }\end{array}$} & $\begin{array}{l}\text { Delegation of people } \\
\text { management } \\
\text { operations across the } \\
\text { team and organization }\end{array}$ & Concern & $\begin{array}{l}\text { Distributing the activities to } \\
\text { parts of the organization and } \\
\text { development teams }\end{array}$ & Case 1,2 & - & - \\
\hline & $\begin{array}{c}\text { Career path } \\
\text { development }\end{array}$ & Concern & $\begin{array}{l}\text { Adding positions based on the } \\
\text { new way of working }\end{array}$ & Case 1,2 & - & - \\
\hline & \multirow[t]{2}{*}{$\begin{array}{l}\text { Dependence upon } \\
\text { individuals }\end{array}$} & Concern & $\begin{array}{l}\text { Minimizing the dependence } \\
\text { through knowledge capture, } \\
\text { knowledge sharing and staff } \\
\text { backup }\end{array}$ & Case 1,2 & - & $\begin{array}{l}\text { Agile principles } \\
\text { discourage } \\
\text { documentation }\end{array}$ \\
\hline & & Concern & $\begin{array}{l}\text { Utilizing documentation, } \\
\text { process and tool capabilities }\end{array}$ & Case 1,2 & - & $\begin{array}{c}\text { Agile principles } \\
\text { discourage using } \\
\text { documentation, process } \\
\text { and tool }\end{array}$ \\
\hline & $\begin{array}{l}\text { Workload and resource } \\
\text { capacity management }\end{array}$ & Concern & $\begin{array}{c}\text { Project and project } \\
\text { management injected into } \\
\text { Scrum }\end{array}$ & $\begin{array}{l}\text { Case 1, } \\
\text { Partially } \\
\text { Case 2 }\end{array}$ & - & $\begin{array}{c}\text { Project and project } \\
\text { management are not } \\
\text { being addressed in } \\
\text { Scrum properly } \\
\end{array}$ \\
\hline & $\begin{array}{l}\text { Performance systems } \\
\text { in Scrum changes } \\
\text { dramatically }\end{array}$ & Concern & $\begin{array}{l}\text { Team level measurement and } \\
\text { assessment should be } \\
\text { preferred with high awareness }\end{array}$ & Case 1,2 & - & $\begin{array}{l}\text { For self-organizing } \\
\text { teams, creating their } \\
\text { own data to reflect } \\
\text { their own performance } \\
\text { with the sake of } \\
\text { personal favors may be } \\
\text { possible }\end{array}$ \\
\hline \multirow[t]{3}{*}{$\begin{array}{c}\text { Project } \\
\text { Management }\end{array}$} & Definition of project & Conflict & $\begin{array}{l}\text { Appreciating the phenomenon } \\
\text { of project and defining it } \\
\text { properly for Scrum }\end{array}$ & Case 1,2 & - & $\begin{array}{l}\text { Scrum does not define } \\
\text { project properly }\end{array}$ \\
\hline & \multirow[t]{2}{*}{$\begin{array}{l}\text { A project management } \\
\text { practices along with } \\
\text { project office and } \\
\text { project manager roles }\end{array}$} & Conflict & $\begin{array}{l}\text { Unifying people around } \\
\text { dedicated project teams from } \\
\text { probably different domains } \\
\text { and managing project } \\
\text { dynamically in an agile way }\end{array}$ & $\begin{array}{l}\text { Author, } \\
\text { Partially } \\
\text { Case } 1,2\end{array}$ & $\begin{array}{c}\text { Against to } \\
\text { COBIT's heavy } \\
\text { plan-driven, } \\
\text { control based } \\
\text { project } \\
\text { management } \\
\text { approach } \\
\end{array}$ & $\begin{array}{c}\text { "How" side of project } \\
\text { management is blur in } \\
\text { Scrum }\end{array}$ \\
\hline & & Conflict & $\begin{array}{c}\text { Locating project manager role } \\
\text { (not necessarily a project } \\
\text { office) when circumstances } \\
\text { call for it }\end{array}$ & Case 1 & $\begin{array}{l}\text { COBIT mandates } \\
\text { project office }\end{array}$ & $\begin{array}{l}\text { Project manager role is } \\
\text { still controversial in } \\
\text { Scrum }\end{array}$ \\
\hline SDLC & $\begin{array}{l}\text { Certain document } \\
\text { contents must be } \\
\text { produced in a certain } \\
\text { order and must be }\end{array}$ & Conflict & $\begin{array}{l}\text { Breaking the order of the } \\
\text { creation of document contents } \\
\text { by taking them to the end of }\end{array}$ & Case 1,2 & $\begin{array}{l}\text { COBIT, in } \\
\text { principle, opposes } \\
\text { to break the order } \\
\text { of the creation of }\end{array}$ & $\begin{array}{l}\text { Scrum does not } \\
\text { mandate such } \\
\text { document contents, }\end{array}$ \\
\hline
\end{tabular}




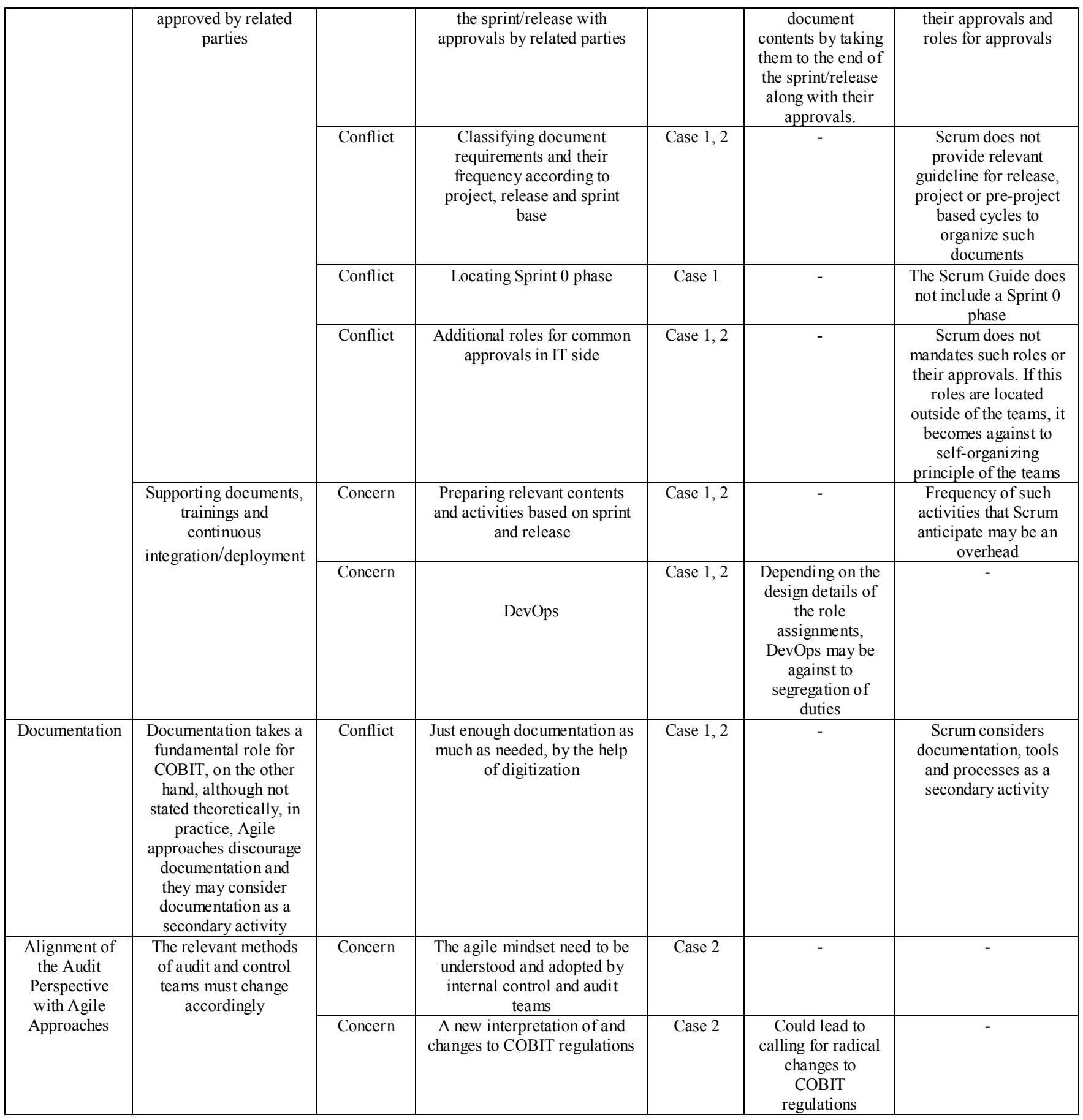

\section{DISCUSSION}

"Conflict" represents that there exists a different and somewhat opposite point of views from the two frameworks. It indicates organizations have to find proper solutions if they prefer to go with these two frameworks simultaneously. "Concern", on the other side, stands for there is need to pay attention to the COBIT requirements especially during a Scrum transformation. Considering there is a clear need to meet COBIT requirement uninterruptedly, such a transformation could be challenging especially with the gradual transitions from traditional models that are accustomed to COBIT. The transition, thus, needs to accomplish a successful transformation and satisfy the relevant $\mathrm{COBIT}$ requirements during and after it.
For the "Concern" type of challenges, COBIT is regarded as the dominant part and Scrum is taken a position to fulfill the relevant COBIT objectives, except for "a new interpretations of and changes to COBIT regulations". For this kind, it is realized that COBIT do not touch to "how" side to meet its objectives and proposes the natural way of working which is common for many organizations. For instance, COBIT expects the adequate operations for the competency management, adhering to codes of ethics, dependence upon individuals, high-level design for the solution developed and providing supporting documents and trainings of new systems for relevant parties. During the implementation of Scrum, organizations are to find their ways of satisfying such requirements when considered Scrum, with its current version, leaves such areas mostly blank and does not fulfill them intentionally or unintentionally. 
For the "Conflict" type of challenges, there should be an endeavor in organizations to find solutions at the middle ground. The possible solutions may be slightly different from the out-of-box COBIT proposals that are mainly a representative of the traditional mentality and Scrum that is a representative of the modern way of development mentality.

As seen, the proposed solutions are not the pure Scrum or COBIT, rather located somewhere between them. Considering this picture, regarding Scrum and COBIT as two contrary sides will not end up with desired solutions. By preserving the two sides with their essence without any negotiations, the possible solutions would be difficult to reach, e.g., rigid regulations of COBIT would crush with the flexible structure of Scrum. Similarly, it would be pointless to try to relocate agility inside COBIT. Finding a middle ground would be possible with understanding the essence of COBIT and Scrum, identifying their contexts and expectations as aimed in this study, and harmonizing them with unique needs of the organizations.

It is worthy to note that each framework have contexts and assumptions. Organizations should be aware of such context and assumption constraints when applying them in their organizations' unique contexts that can naturally be different from those of the frameworks. For instance, in COBIT, the development pipeline is designed for a long time development period, bearing the well-known disadvantages [25]. This is why COBIT proposes to get the approvals from the relevant parties to ensure that this long time development pipeline is on the way. However, such a long pipeline is not the case with the short iterations of Scrum. Additionally, COBIT comes with some sort of assumptions such as a linear progressing in the software development; however, software development does not mostly behave in a linear direction. Thus, organizations should be identifying and thus separating the issues coming from the COBIT's own context that may become similar to the traditional development.

For the Agile way of development, there are context-based disadvantages to tackle as well. The ASD fits and is most likely to succeed within its own "home-ground" [26], called as the "comfort-zone" for Scrum in particular [27]. The illusion of staying at the comfort-zone may have led to thinking that the Agile methods have universal value, that they represent some ultimate recipe, the holy grail of software engineering [28]. However, there rationally may exist places where an absolute agility may be naturally needed, beyond such a "comfort zone" or"Agile sweet spot" [15]. This is why, although Agile methods enjoy their comfort-zone, some organizations have already started to push the agility in software development beyond this out-of-box comfort area $[24,29]$. Injecting Scrum into an environment unfamiliar to it can be regarded such. Adoption and adaptation of Scrum within a COBIT environment may help in this manner, in a way to find a middle ground for organizations that need the different capabilities.

From a higher point of view, organizations should be able to take the advantages of varying adjectives (abilities) according to their needs [34]. While 'agility' in the current state of the software development enjoy its comfort-zone alone, organizations today still need to have some other abilities such as being disciplined and sustainable that the Agile world intentionally or unintentionally ignores [15]. It is suggested to search for the proper integration and harmony of agile mindset, theoretically and practically with other realities and needs of organizations, and the same goes in for the versa vise [34]. This approach is also parallel to the view of Conboy and Fitzgerald [30] whom study of experts' opinion on Agile methods notes that "the very name agile suggests that the method should be easily adjusted to suit its environment".

There has been already a clear polarization between the Agile and traditional management communities for many years. Apart from this, the sufficient integration of Agile and traditional approaches calls for the major and fundamental shifts in thinking. However, as an indication, the traditional IT frameworks and guidelines such as PMBOK and ITIL has started to incorporate more about Agile in their recent publications. For instance, the last version of PMBOK, the 6 . version [31], and the Agile Practice Guide released by the Project Management Institute pose some minor yet considerable attempts to create a more integrated approach with Agile project management. ITIL 4 framework has also evolved to reflect some similarities with the Agile principles in its guiding principles [32]. For the latest version of COBIT, COBIT 2019, [33] states that it addresses new trends in technology such as DevOps and Agile development concepts.

These initiatives can be considered as a kind of response to the needs of organizations that want to have these two worlds at the same time. Therefore, the number of such initiatives is likely to increase. For today, while this combination remains at the level of inclusion of some concepts without the sufficient integration, this convergence in the near future will probably advance.

\section{CONCLUSION AND FUTURE WORK}

The study provides a picture via the list of challenges and solutions for Scrum and COBIT coexistence. The study reminds to consider the opportunities and benefits of Scrum along with the challenges in integrating it with the COBIT practices [1]. Though the agility is necessary for organizational adaptation, control is also necessary for high assurance of survival of organizations. After all, practitioners need to strike a balance between these two seemingly "contrary" but also complementing interests in their work environments. Even though these two sides apparently seem "contrary", the options are not a binary or mutually exclusive. Blending them with a right balance according to each organization's unique context is a natural need of organizations. Since it is not possible for the frameworks to predict these unique needs of each organization up-front, it would be right for the organization to tailor them according to their needs.

As a solution to striking a balance, it is actually possible to tailor Scrum. Following the idea that the more a particular project's conditions differ from the home-ground conditions, the more risk in using one approach in its pure form [26], COBIT can accompany Scrum during its unknown and compelling journey. On the other side, with the question of how much COBIT (v.4.1) is suitable to support being agile in today's environments, organizations should choose the option of tailoring COBIT in a more agile way, if possible.

We assume the contributions this work would be valuable especially for the practitioners before the implementation of Scrum in COBIT environments. COBIT are phone to apply in disciplined, large-scaled and traditional environments. The organizations bearing one of those characteristics yet not applying COBIT can also benefit from this study. As a future 
work, we plan to provide the similar work of this study with the newer versions of COBIT.

\section{REFERENCES}

[1] N. Ozkan, "Risks Challenges and Issues in a Possible Scrum and COBIT Marriage", Software Engineering Conference (APSEC) 2015 Asia-Pacific, pp. 111-118, 2015.

[2] N. Ozkan, A. Tarhan and C. Kucuk, "Scrum at Scale in a COBIT Compliant Environment: The Case of Turkiye Finans IT", XP2017, 2017.

[3] N. Ozkan, N., "Scrum Integrated SDLC Processes of Turkiye Finans IT in a COBIT Compliant Environment", Turkish National Software Engineering Symposium (UYMS), pp. 126-134, 2017

[4] "Cobit 4.1", ISACA, 2007.

[5] "COBIT Global Regulatory and Legislative Recognition", ISACA, 2014.

[6] "13th annual state of agile survey", 2019, [online] Available: https://stateofagile.com/\#ufh-i-521251909-13th-annual-state-of-agilereport $/ 473508$

[7] T. Dingsøyr and N. B. Moe, "Towards principles of large-scale agile development", International Conference on Agile Software Development, 2014

[8] B. Boehm and R. Turner, "Using risk to balance agile and plan-driven methods", Computer., vol. 36, no. 6, pp. 57-66, 2003

[9] V. Kannan, S. Jhajharia, S. and S. Verma, "Agile vs waterfall: A Comparative Analysis", International Journal of Science, Engineering and Technology Research (IJSETR), vol. 3, no. 10, pp. 2680-2686, 2014.

[10] D. A. Aguillar, I. Murakami, P. Manso, and P. T. Aquino, "Small Brazilian Business and IT Governance: Viability and Case Study", Information Technology for Management. Ongoing Research and Development, pp. 173-193, 2017.

[11] J. Sutherland and K. Schwaber, "The Scrum guide. the definitive guide to Scrum: The rules of the game", 2017, [online] Available: https://www.scrum.org/resources/scrum-guide.

[12] N. Ozkan and C. Kucuk, "A Systematic Approach to Project Related Concepts of Scrum", Revista de Management Comparat International, vol. 17 , no. 4, 2016.

[13] T. Clear, "Documentation and agile methods: striking a balance", SIGCSE Bull, vol. 35, no. 2, pp. 12-13, 2003.

[14] S. Nerur, R. Mahapatra and G. Mangalaraj, "Challenges of migrating to agile methodologies", Commun. ACM, vol. 48 , no. 5 , pp. $72-78$, 2005.

[15] N. Ozkan, and A. Tarhan, "An Investigation into Increased Agility by Balancing Agile and Traditional Process Approaches", Turkish National Software Engineering Symposium (UYMS), 2018.

[16] G. Parry, L. Newnes, and X. Huang, "Goods, products and services", Service design and delivery, pp. 19-29, Springer: Boston, MA, 2011.

[17] K. Schwaber, "Agile Project Management with Scrum", Redmond: Microsoft Press, 2004.

[18] PMBOK Guide, Project Management Institute, 2013.

[19] "COBIT Control Practices: Guidance to Achieve Control Objectives for Successful IT Governance 2nd edn", ISACA, 2007.

[20] K. Beck et al., "Agile manifesto", 2001, [online] Available: http://agilemanifesto.org.

[21] N. Sekitoleko, et. al., "Technical dependency challenges in large-scale agile software development", International Conference on Agile Software Development, pp. 46-61, 2014.

[22] M. C Paulk, "Agile methodologies and process discipline", Institute for Software Research, pp.15-18, 2002.
[23] C. D. O Melo, C. Santana, and F. Kon, "Developers motivation in agile teams", 38th Euromicro Conference on Software Engineering and Advanced Applications, pp. 376-383, 2012.

[24] R. Hoda, P. Kruchten, J. Noble and S. Marshall, "Agility in context", ACM Sigplan Notices, vol. 45, no. 10, pp. 74-88, 2010.

[25] M. Stoica, M. Mircea and B. Ghilic-Micu, "Software development: Agile vs. traditional", Inform. Econ., vol. 17, pp. 64-76, 2013.

[26] B. Boehm, and R. Turner, Balancing Agility and Discipline: Evaluating and Integrating Agile and Plan-Driven Methods, Proc. the 26th International Conference on Software Engineering, pp. 718-719, 2004.

[27] R. Lyon and M. Evans, "Scaling up pushing scrum out of its comfort zone", Agile 2008 Conference, pp. 395-400, 2008.

[28] P. Kruchten, "Contextualizing agile software development", Journal of Software: Evolution and Process, vol. 25, no:4, pp. 351-361, 2013.

[29] T. Dingsøyr and N. B. Moe, "Research challenges in large-scale agile software development", ACM SIGSOFT Software Engineering Notes, vol. 38 , no. 5 , pp. $38-39,2013$.

[30] K. Conboy and B. Fitzgerald, "The views of experts on the current state of agile method tailoring", IFIP International Working Conference on Organizational Dynamics of Technology-Based Innovation, pp. 217-234, 2007

[31] Project Management Institute A Guide To The Project Management Body Of Knowledge (PMBOK-Guide) - Sixth version, Pennsylvania, USA:Project Management Institute, Inc, 2017.

[32] M: Corona, "ITIL 4, IT Service Management and Agile", Axelos, 2019, [Online]. Available: https://www.axelos.com/case-studies-andwhite-papers/itil-4-it-service-management-and-agile.

[33] J. Lainhart, "Introducing COBIT 2019: The Motivation for the Update", 2018, [Online]. Available: https://www.isaca.org/resources/news-and-trends/newsletters/cobitfocus/2018/introducing-cobit-2019-the-motivation-for-the-update

[34] N. Ozkan, "Imperfections Underlying the Manifesto for Agile Software Development", 1st International Informatics and Software Engineering Conference (UBMYK), 2019.

[35] N. Ozkan, A.K. Tarhan, "Investigating Causes of Scalability Challenges in Agile Software Development from a Design Perspective", 1st International Informatics and Software Engineering Conference (UBMYK), 2019.

[36] A. C. Amorim, M. M. da Silva, R. Pereira and M. Gonçalves, "Using agile methodologies for adopting COBIT", Information Systems, 101496, 2020.

[37] N. Ozkan, "People Management Issues in Scrum from COBIT Perspective", the Workshop on Alternative Workforces for Software Engineering (WAWSE), pp. 54, 2015.

[38] C. Montenegro, and R. Arévalo, "Software development governance for VSE-SCRUM teams: Model and evaluation in a developing country", International Conference on Software Engineering and Information Management, pp. 1-5, 2018.

[39] N. Ozkan and C. Kucuk, "Integrating Project Related Concepts with the Core of Scrum. International Management Conference, pp. 221$230,2017$.

[40] N. Zabkar and V. Mahnic, "Using COBIT indicators for measuring Scrum-based software development", WSEAS Transactions on Computers, vol. 7, no. 10, pp. 1605-1617, 2008.

[41] A. Przybyłek, W. Kowalski, Utilizing online collaborative games to facilitate Agile Software Development, Proceedings of the 2018 Federated Conference on Computer Science and Information Systems, M. Ganzha, L. Maciaszek, M. Paprzycki (eds). ACSIS, Vol. 15, pp. 811-815, 2018, DOI: 10.15439/2018F347. 